\title{
The impact of metformin use on recurrence and cancer-specific survival in clinically localized high-risk renal cell carcinoma
}

\author{
A. Ari Hakimi, MD; Ling Chen, MD; ${ }^{\dagger}$ Philip H. Kim, MD; Daniel Sjoberg, MD; ${ }^{\dagger}$ Leonard Glickman, MD;* \\ Marc R. Walker, MD; ${ }^{*}$ Paul Russo, MD*
}

*Urology Service, Department of Surgery, Memorial Sloan-Kettering Cancer Center, New York, NY; †Department of Epidemiology and Biostatistics, Memorial Sloan-Kettering Cancer Center, New York, NY

Cite as: Can Urol Assoc J 2013;7(11-12):e687-91. http://dx.doi.org/10.5489/cuaj.1447

Published online November 8, 2013.

\section{Abstract}

Background: Recent data suggest that metformin may have antineoplastic properties. We sought to determine what effect metformin had on recurrence and cancer-specific survival (CSS) rates of patients with clinically localized pT2 and pT3 renal cell carcinoma (RCC) following radical or partial nephrectomy.

Methods: We obtained data on 784 patients who underwent partial or radical nephrectomy for pT2 or pT3 tumours at our centre between 1996 and 2011. Patients with benign masses, nodal positivity, or metastasis at the time of surgery were excluded. Using a competing-risks regression model, we compared differences in probability of recurrence between patients who used metformin versus those who did not.

Results: The patients on metformin at the time of surgery had worse disease recurrence than patients not on metformin. However, this was not statistically significant on multivariate analysis when controlling for age, race, body mass index, glomerular filtration rate, and tumour stage and grade (hazard ratio [HR], 1.22; 95\% confidence interval $[\mathrm{Cl}], 0.66-2.27[p=0.5]$ ). Metformin use was associated with a lower risk of cancer-specific mortality, but this was not statistically significant when adjusted for clinical and tumour characteristics (HR, 0.76; 95\% Cl 0.21-2.7 [ $p=0.7])$. Limitations include the retrospective nature of the study and the lack on information on duration of metformin use.

Conclusions: Metformin use at the time of surgery for high-risk clinically localized RCC is not protective in terms of recurrence or CSS. Further studies should be done to confirm these findings and determine what effect concurrent metformin use might have on improved response to targeted therapies in the metastatic setting.

\section{Introduction}

Renal cell carcinoma (RCC) is the sixth leading cause of cancer death in the United States, with nearly one-third of patients presenting with metastases. ${ }^{1}$ Disease recurrence after resection for a localized tumour remains a significant issue. Progression-free probability rates are about $80 \%$ for patients with pathologic stage T2 tumours and $57 \%$ to $67 \%$ for patients with pT3 tumours. ${ }^{2}$ Current prediction models for recurrence and cancer-specific outcomes in RCC rely largely on pathologic tumour characteristics and patient performance status. ${ }^{3-5}$

Recent data suggest that metformin may aid in cancer prevention and potentially prevent tumour recurrence. ${ }^{6,7}$ In vitro and in vivo evidence suggest anti-neoplastic effects of metformin on breast cancer, ${ }^{8}$ colon cancer, ${ }^{9}$ and most recently RCC. ${ }^{10}$ The putative mechanism is through inhibition of the AKT/mammalian target of rapamycin (mTOR) signaling pathway via activation of adenosine monophosphate-activated protein kinase (AMPK), a negative regulator of the mTOR pathway. We sought to determine the effect of metformin use on the risk of recurrence following resection of clinically localized higher-risk RCC, which we defined as pT2 and pT3 according to the TNM Classification of Malignant Tumors system by the American Joint Committee on Cancer/Union for International Cancer Control. ${ }^{11}$

\section{Methods}

In our institutional review board-approved retrospective study, we obtained data of 860 patients with pT2 and pT3 clinically localized renal tumours from our RCC database. Of the 860 patients who underwent surgical resection via nephrectomy or partial nephrectomy between 1996 and 2011, 76 patients with oncocytoma or other benign masses were excluded from the study. For patients who died from kidney cancer before documentation of metastasis, their date of death was considered as their date of recurrence $(n=27)$. Recurrences were defined as those diagnosed either radiographically or pathologically. If a patient was taking medications at the time of surgical resection, these were factored in. 
We hypothesized that metformin use is associated with lower recurrence of kidney cancer and cancer-specific mortality. The primary aim was to investigate the differences in the probability of recurrence and cancer-specific mortality between patients who used metformin and those who did not. Baseline characteristics were compared between metformin and non metformin patients using Pearson's chisquare for categorical variables or Mann-Whitney-Wilcoxon for continuous variables. To explore differences in recurrence and cancer-specific mortality, we used a competingrisks regression model with death from other causes as the competing risk. Survival time was calculated from the time of surgery. The two outcomes were examined separately in models adjusted for factors related to diabetes, including age at surgery, body mass index (BMI), race (black, white, Asian, or other), preoperative glomerular filtration rate (GFR), pathology (T2 vs. T3) and Fuhrman nuclear grade (high vs. low) when appropriate. Recurrence-free and cancer-specific survival (CSS) was estimated with the cumulative incidence function with death from other causes as a competing risk and compared using a modified $x^{2}$ test.

The main analysis was based on data from different histological subtypes of renal tumours. We also performed a subgroup analysis restricted to the most prevalent histology, which was clear cell carcinoma. All statistical analyses were conducted using STATA 11.0 (Statacorp, College Station, TX) and and R (R Foundation for Statistical Computing, ${ }^{12}$ ) with the cmprsk package.

\section{Results}

We identified baseline characteristics for the 784 patients in our study (Table 1). Less than 1 in 10 patients used metfor$\min (7 \%)$. There were no major differences between patients who used metformin and those who did not, other than the former group having a higher median BMI (33 vs. 28). The proportion of recurrence were the same among nonmetformin and metformin users (153 [21\%] vs. 11 [20\%], respectively). Median follow-up was 3.4 years for patients who did not have a recurrence or die of other causes. Patients who used metformin had a higher risk for recurrence than in patients who did not; however, this was not statistically significant on multivariable analysis when controlling for age, race, $\mathrm{BMI}$, preoperative GFR, and tumour stage and grade (hazard ratio [HR], 1.22; 95\% confidence interval [Cl], 0.66$2.27[p=0.5])$. Of those who died from RCC, the median time to recurrence for the 3 metformin users was 0.94 years and median time for non-metformin users $(n=75)$ was 0.95 years. None of the predictors included in our model, except for pathologic grade, were significant (Table 2).

On follow-up, 78 patients died from kidney cancer, of which 3 patients used metformin. In total, 106 patients died from causes other than kidney cancer, of which 91

\begin{tabular}{|c|c|c|c|}
\hline & $\begin{array}{l}\text { No metformin } \\
\text { use } n=729\end{array}$ & $\begin{array}{l}\text { Metformin use } \\
n=55\end{array}$ & $p$ value \\
\hline \multicolumn{4}{|l|}{$\begin{array}{l}\text { Characteristics at } \\
\text { surgery }\end{array}$} \\
\hline Age & $\begin{array}{c}62 \\
\text { (range: } 53-71 \text { ) }\end{array}$ & $\begin{array}{c}62 \\
\text { (range: } 53-70 \text { ) }\end{array}$ & $>0.95$ \\
\hline Male & $510(70 \%)$ & $39(71 \%)$ & 0.9 \\
\hline \multicolumn{4}{|l|}{ Race } \\
\hline White & $644(88 \%)$ & $50(91 \%)$ & 0.6 \\
\hline Black & $42(6 \%)$ & $2(4 \%)$ & 0.5 \\
\hline Asian & $29(4 \%)$ & $2(4 \%)$ & 0.9 \\
\hline Other/Unknown & $14(2 \%)$ & $1(2 \%)$ & $>0.95$ \\
\hline BMI $\left(\mathrm{kg} / \mathrm{m}^{2}\right)$ & $\begin{array}{c}28 \\
\text { (range: } 25-32 \text { ) }\end{array}$ & $\begin{array}{c}33 \\
\text { (range: } 29-38 \text { ) }\end{array}$ & $<0.0001$ \\
\hline $\begin{array}{l}\text { Preoperative GFR } \\
\left(\mathrm{ml} / \mathrm{min} / 1.73 \mathrm{~m}^{2}\right)\end{array}$ & $\begin{array}{c}65 \\
\text { (range: } 54-76 \text { ) }\end{array}$ & $\begin{array}{c}61 \\
\text { (range: } 52-74 \text { ) }\end{array}$ & 0.3 \\
\hline \multicolumn{4}{|l|}{ Pathological stage } \\
\hline $\mathrm{T} 2$ & $172(24 \%)$ & $10(18 \%)$ & 0.4 \\
\hline T3 & $557(76 \%)$ & 45 (82\%) & 0.4 \\
\hline $\begin{array}{l}\text { High pathological } \\
\text { grade }\end{array}$ & $349(59 \%)$ & $30(61 \%)$ & 0.8 \\
\hline
\end{tabular}

were from unknown causes. The median follow-up time was 3.6 years for survivors. Although metformin use was associated with a lower risk of cancer-specific mortality, our Cls were wide and not statistically significant when adjusted for clinical and tumour characteristics $(\mathrm{HR}, 0.76 ; 95 \% \mathrm{Cl}$, 0.21-2.70 [ $p=0.7]$ ) (Fig. 1, Fig. 2).

Subgroup analyses of patients with clear cell carcinoma $(n=544)$ showed results similar to those observed in the main cohort analysis. Baseline characteristics resembled the main cohort. We found that patients with clear cell carcinoma using metformin had 1.7 times the risk of recurrence $(95 \% \mathrm{Cl}, 0.89-3.05)$ and no difference in risk of cancerspecific mortality (HR 1.03 95\% Cl, 0.27-3.77) after inclusion of the covariates on multivariate analysis. However, these effects were not statistically significant $(p=0.1$ and $p=1$, respectively).

We then explored whether any differences seen in patients who used metformin could, in fact, be due to diabetes by assessing differences in recurrence between diabetics and non-diabetics who did not use metformin. There was no statistically significant difference between the 2 groups (HR, $1.02 ; 95 \% \mathrm{Cl}, 0.59-1.74[p=1])$ after adjusting for age, race, $\mathrm{BMI}, \mathrm{GFR}$, and tumour stage and grade.

Given that metformin use is dependent on renal function, it is possible that patients with large tumours on metformin preoperatively may have stopped metformin postoperatively due to declining kidney function from treatment of their large tumours. Of the 55 patients on metformin, a total of 23 patients stopped metformin before last follow-up and 
Table 2. Multivariable competing-risks regression analysis to evaluate predictors of recurrence and cancer-specific mortality following resection

\begin{tabular}{|c|c|c|c|c|c|c|}
\hline \multirow[b]{2}{*}{ Predictor } & \multicolumn{3}{|c|}{ Recurrence } & \multicolumn{3}{|c|}{ Cancer-specific mortality } \\
\hline & HR & $95 \% \mathrm{Cl}$ & $p$ value & HR & $95 \% \mathrm{Cl}$ & $p$ value \\
\hline Metformin use & 1.22 & $0.66,2.27$ & 0.5 & 0.76 & $0.21,2.70$ & 0.7 \\
\hline Age per 10 years & 0.90 & $0.77,1.05$ & 0.17 & 0.84 & $0.69,1.03$ & 0.096 \\
\hline Race (Black vs. other) & 0.71 & $0.30,1.66$ & 0.4 & 0.32 & $0.06,1.78$ & 0.2 \\
\hline $\mathrm{BMI}\left(\mathrm{kg} / \mathrm{m}^{2}\right)$ & 0.99 & $0.96,1.02$ & 0.5 & 0.99 & $0.94,1.04$ & 0.6 \\
\hline Preoperative GFR per 10 units $\left(\mathrm{mL} / \mathrm{min} / 1.73 \mathrm{~m}^{2}\right)$ & 0.98 & $0.88,1.09$ & 0.7 & 0.95 & $0.81,1.12$ & 0.5 \\
\hline Pathologic stage (T3 vs. T2) & 1.30 & $0.85,2.00$ & 0.2 & 1.36 & $0.75,2.49$ & 0.3 \\
\hline Grade (high vs. low) & 2.57 & $1.80,3.67$ & $<0.0005$ & 4.51 & $2.50,8.14$ & $<0.0005$ \\
\hline
\end{tabular}

13 stopped immediately after surgery. To eliminate the effect caused by patients who stopped metformin shortly after surgery, a landmark analyses was performed 6 and 12 months after surgery was completed. We excluded 73 patients who were not at risk of the event at the 6-month landmark and 131 patients who were not at risk of the event at the 12-month landmark. The 6-month landmark analysis showed similar estimates for recurrence and cancer-specific mortality as our main analysis (recurrence: HR 1.22, 95\% $\mathrm{Cl} 0.65-2.28, p=0.5$, CSS: HR 0.74, 95\% Cl 0.20-2.70, $p=0.7)$. Metformin use was associated with a much larger improvement in CSS in the 12-month landmark analysis (HR 0.53 95\% 0.12-2.34, $p=0.4$ ), although the association remained not statistically significant. Estimates for recurrence were not importantly affected (HR $1.20,95 \% \mathrm{CI} 0.62$ 2.32, $p=0.6)$.

\section{Discussion}

Metformin was discovered during the 1920s in a search for guanidine-containing compounds with glycemic control properties. It is a very commonly used drug, and it is often the first-line approach to treat newly diagnosed type 2 diabetes. The exact mechanism of action of metformin remains unclear, but it is believed to involve AMPK. ${ }^{13}$ AMPK acts as a cellular energy-supply sensor and is activated under stress conditions that deplete cellular adenosine-5'-triphosphate (ATP). Malignant cells typically acquire features of enhanced metabolism due to increased DNA synthesis and protein translation, which can be targeted in cancerous cells because of changes in ATP level. ${ }^{14}$ AMPK has been linked to the phosphatidylinositol-3 kinase/AKT/mTOR signaling cascade, which is an essential pathway for cell growth by activating tuberous sclerosis complex $2 .{ }^{15}$ AMPK activation directly inhibits phosphorylation and subsequent activation of the mTOR Complex 1 (mTORC1). ${ }^{16}$ Metformin may also act independently of AMPK to directly inhibit mTORC $1 .{ }^{17}$

RCC is characterized by over-activation of the AKT/mTOR pathway, and several studies have demonstrated the efficacy of targeting this pathway for the treatment of metastatic or unresectable disease. ${ }^{18,19}$ Liu and colleagues assessed the in vitro effects of metformin on 2 RCC cell lines. ${ }^{10}$ The investi-

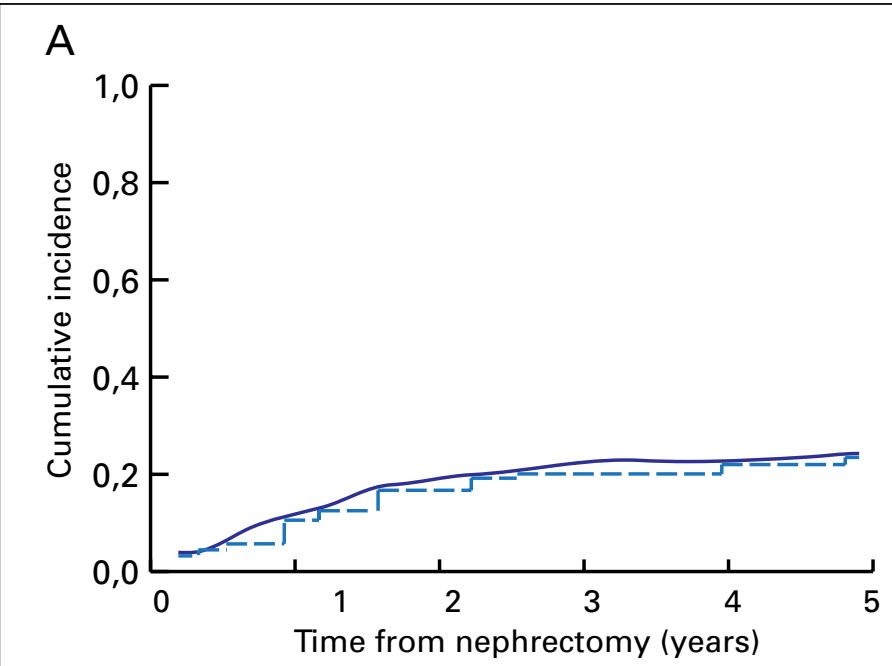

B

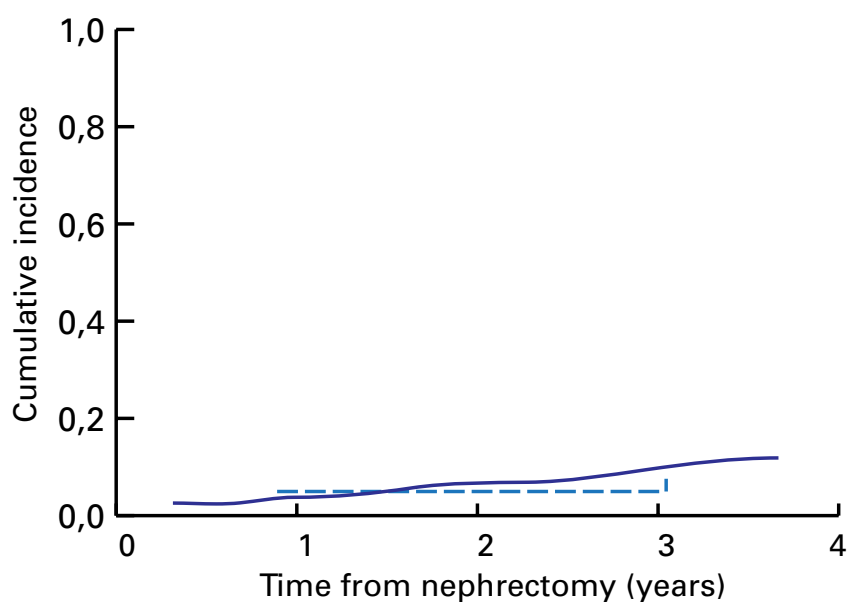

Fig. 1. Cumulative 5-year incidence of recurrence (a) and cancer-specific survival (b) for metformin and non-metformin users. (Metformin=dashed line, Nonmetformin users=solid line) 


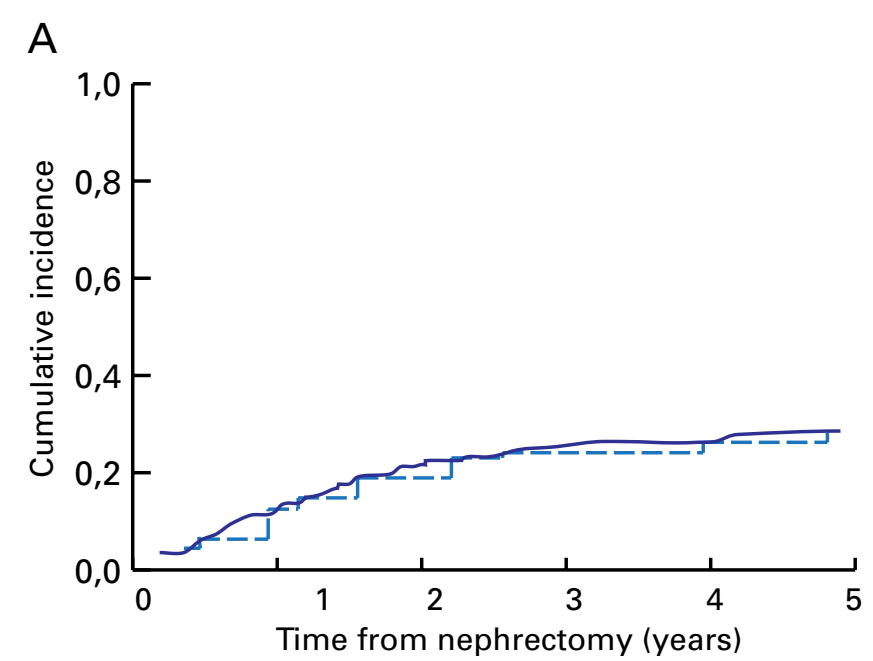

\section{B}

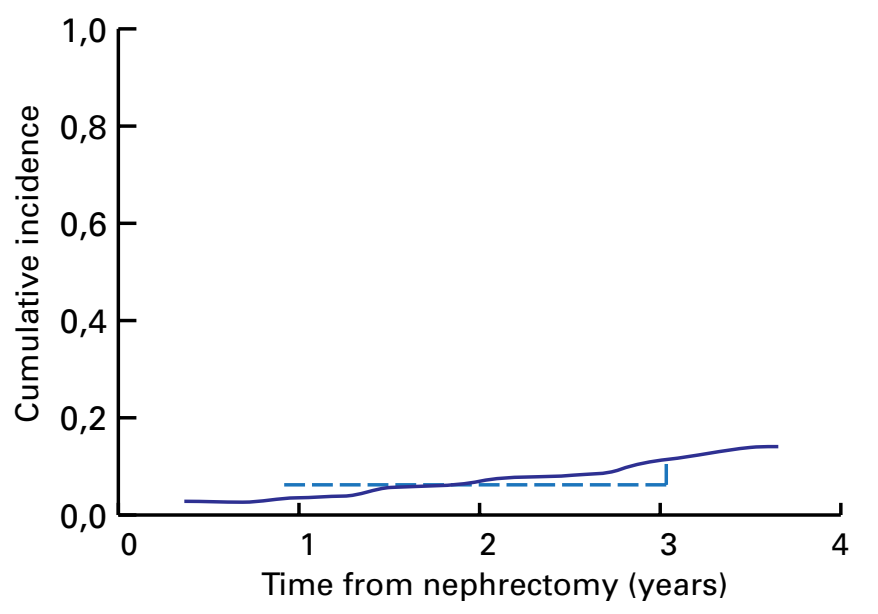

Fig. 2. Cumulative 5 -year incidence of recurrence (a) and cancer-specific survival (b) for metformin and non-metformin users with clear cell carcinoma. (Metformin=dashed line, Non-metformin users=solid line)

gators found that metformin inhibited cell proliferation and induced cell cycle arrest via down-regulation of cyclin D1. Additionally, they confirmed that metformin activated AMPK via phosphorylation and inhibited mTOR signaling. Finally, they found that daily use of metformin prevented tumour growth in a nude mouse xenograft model.

While metformin has been shown to have anti-neoplastic properties in vitro and possibly in vivo, there are also emerging data from large epidemiologic studies supporting the hypothesis that metformin may reduce cancer risk as primary prevention and by reducing the risk of recurrence. In an observational cohort study of nearly 400000 patients from Scotland, Libby and colleagues ${ }^{6}$ identified type 2 diabetics who began using metformin between 1994 and 2003 and matched each user individually by year of diagnosis to type 2 diabetics who did not use metformin. Of the 4085 diabetics who used metformin, $7.3 \%$ were diagnosed with cancer compared with $11.6 \%$ of the 4085 diabetics who did not use metformin; median times to cancer were 3.5 and 2.6 years, respectively $(p<0.001)$. A significantly reduced risk of cancer was associated with metformin (HR, 063; 95\% $\mathrm{Cl}, 0.53-0.75$ ) after adjusting for sex, age, BMI, hemoglobin A1C, deprivation, smoking, and other drug use. In a nested case-control study of 1340 type 2 diabetics who were treated with insulin, Monami and colleagues found that a reduced incidence of cancer was associated with exposure to metformin and not sulfonylureas, (odds ratio [OR], 0.46; $95 \%$ $\mathrm{Cl}, 0.25-0.85$ [ $p=0.014$ for metformin]; OR, 0.75; 95\% Cl, $0.39-1.45$ [ $p=0.40$ for sulfonylureas]) after adjusting for glargine use, comorbidity, and total insulin doses. ${ }^{20}$

There is emerging evidence that patients who take metformin have better response rates to standard therapy than those who do not. A recent study of over 2500 women with breast cancer reported higher pathologic complete response
(pCR) rates to neo-adjuvant systemic therapy in diabetic patients receiving metformin (pCR 24\%) than both diabetic and non-diabetic patients not receiving metformin (pCR 8\%, pCR $16 \%$, respectively) $(p=0.02)^{7}$

Metformin use, however, has not necessarily been shown to improve overall survival (OS) or CSS. In a recent study of 1448 patients with triple receptor-negative breast cancer who received adjuvant chemotherapy at MD Anderson Cancer Center, Bayraktar and colleagues assessed the impact of metformin on distant metastasis-free survival (DMFS), recurrence-free survival (RFS), and OS. ${ }^{21}$ At a median followup of 62 months, there were no significant differences with regard to 5-year DMFS $(p=0.23)$, RFS $(p=0.38)$, and OS $(p=0.58)$ among the 3 groups. The authors did find that patients who did not use metformin had a higher risk of distant metastases. Presently, there have been no systematic epidemiologic studies to assess the impact of metformin on RCC development or recurrence.

Given the epidemiological and biological plausibility for RCC interaction, we assessed the impact of metformin use on recurrence in patients who underwent definitive management for higher-risk RCC, defined as pathologic stage T2 and above. In our study, 11 of the 164 recurrences (7\%) occurred in patients taking metformin with a median follow-up of 3.1 years. In terms of recurrences, our study found no significant differences between patients who used metformin and those who did not, with patients who used metformin having a non-significant increase in recurrence when controlling for age, race, $\mathrm{BMI}$, preoperative GFR, and tumour stage and grade (HR, 1.22; 95\% Cl, 0.66-2.27 [ $p=0.5]$ ) (Table 2, Fig. 1 ). With regards to CSS, there was no statistically significant difference between the 2 groups after adjusting for clinical and tumour characteristics (HR, 0.76; 95\% Cl 0.21-2.7 $[p=0.7])$. Possible explanations for the higher recurrence 
rates, but improved CSS, may have to do with the type and location of recurrences in the metformin cohort. However, the small sample size precludes any definitive conclusions. We further explored the effect of diabetes on recurrence among patients who used metformin and those who did not and found no differences after adjusting for covariates. Our sub-analysis of the 544 clear cell tumours showed results similar to those of the larger cohort, with a tendency toward increased recurrence in patients who used metformin (HR, $1.7 ; 95 \% \mathrm{Cl}, 0.89-3.05[p=0.09])$, and no difference in CSS (HR, 0.9; 95\% Cl, 0.27-3.05 [ $p=0.5]$ ) (Fig. 2).

The overall lack of effect of metformin in the prevention of RCC recurrence has several possible explanations. Metformin use may only partially suppress the mTOR pathway by inhibiting mTORC1, possibly selecting for tumours that rely on AKT for proliferation via mTORC2. ${ }^{22}$ Moreover, it is conceivable that over time these patients have developed tumours that are selectively resistant to mTOR inhibition, similar to the mTOR resistance seen in the metastatic setting with continuous use. ${ }^{23}$ Further studies on metformin use and response to mTOR inhibitors are certainly warranted, given the possibility that these tumours may act in an mTOR pathway-independent fashion.

There are some important limitations to our study. Medication assessment was reliant on data from our database, and due to the retrospective nature of our study, no data on the duration of metformin use, which may have had a significant effect on tumour response, were available. Further, we could not account for the severity of diabetes and affect of chronic hyperglycemia on cancer specific outcomes. Additionally, we were not able to fully track all recurrences or cancer-specific deaths occurring outside of our institution.

\section{Conclusions}

Metformin use is not associated with effects on recurrence or cancer-specific mortality following resection for higher-risk clinically localized RCC. Further studies should be done to confirm these findings and determine what effect concurrent metformin use might have on improved response to targeted therapies in the metastatic setting.

Acknowledgement: This work has been supported by the Sidney Kimmel Center for Prostate and Urologic Cancers, by funds provided by David H. Koch through the Prostate Cancer Foundation, the National Cancer Institute T32 CA082088-12 training grant (Dr. Hakimi).

Competing interests: Dr. Hakimi, Dr. Chen, Dr. Kim, Dr. Sjoberg, Dr. Glickman and Dr. Walker all declare no competing financial or personal interests. Dr. Russo is a consultant for Wilex AG.

This paper has been peer-reviewed.

\section{References}

1. Siegel R, Naishadham D, Jemal A. Cancer statistics, 2012. CA Cancer I Clin 2012;62:10-29. http:// dx.doi.org/10.3322/caac.20138

2. Stephenson AJ, Chetner MP, Rourke K, et al. Guidelines for the surveillance of localized renal cell carcinoma based on the patterns of relapse after nephrectomy. J Urol 2004;172:58-62. http://dx.doi. org/10.1097/01.ju.0000132126.85812.7d

3. Sorbellini M, Kattan MW, Snyder ME, et al. A postoperative prognostic nomogram predicting recurrence for patients with conventional clear cell renal cell carcinoma. J Urol 2005;173:48-51. http://dx.doi. org/10.1097/01.ju.0000148261.19532.2c

4. Thompson RH, Leibovich BC, Lohse CM, et al. Dynamic outcome prediction in patients with clear cell renal cell carcinoma treated with radical nephrectomy: the D-SSIGN score. J Urol 2007;177:477-80. http:// dx.doi.org/10.1016/i.juro.2006.09.057

5. Zisman A, Pantuck AJ, Wieder J, et al. Risk group assessment and clinical outcome algorithm to predict the natural history of patients with surgically resected renal cell carcinoma. J Clin Oncol 2002;20:4559-66. http://dx.doi.org/10.1200/JC0.2002.05.111

6. Libby G, Donnelly LA, Donnan PT, et al. New users of metformin are at low risk of incident cancer: a cohort study among people with type 2 diabetes. Diabetes Care 2009;32:1620-5. http://dx.doi. org/10.2337/dc08-2175

7. Jiralerspong S, Palla SL, Giordano SH, et al. Mefformin and pathologic complete responses to neoadjuvant chemotherapy in diabetic patients with breast cancer. J Clin Oncol 2009;27:3297-02. http://dx.doi. org/10.1200/JC0.2009.19.6410

8. Zakikhani $M$, Dowling R, Fantus IG, et al. Metformin is an AMP kinase-dependent growth inhibitor for breast cancer cells. Cancer Res 2006;66:10269-73. http://dx.doi.org/10.1158/0008-5472.CAN-06-1500

9. Buzzai $M$, Jones RG, Amaravadi RK, et al. Systemic treatment with the antidiabetic drug metformin selectively impairs p53-deficient tumor cell growth. Cancer Res 2007;67:6745-52. http://dx.doi. org/10.1158/0008-5472.CAN-06-4447

10. Liu J, Li M, Song B, et al. Metformin inhibits renal cell carcinoma in vitro and in vivo xenograft. Urol Oncol 2013;31:264-70. httrp://dx.doi.org/10.1016/j.urolonc.2011.01.003. Epub 2011 Jun 15.

11. Edge SB, Compton CC. The American Joint Committee on Cancer: the 7th edition of the AJCC cancer staging manual and the future of TNM. Ann Surg Oncol 2010;17:1471-4.

12. The R Project for Statistical Computing. http://www.R-project.org. Accessed October 22, 2013.

13. Sun Y, Connors KE, Yang DQ. AICAR induces phosphorylation of AMPK in an ATM-dependent, LKB1independent manner. Mol Cell Biochem 2007;306:239-45. http://dx.doi.org/10.1007/s11010007-9575-6

14. Avdulov $S$, LiS, Michalek V, et al. Activation of translation complex elF4F is essential for the genesis and maintenance of the malignant phenotype in human mammary epithelial cells. Cancer Cell 2004;5:553-63. http://dx.doi.org/10.1016/i.ccr.2004.05.024

15. Hay N. The Akt-mTOR tango and its relevance to cancer. Cancer Cell 2005;8:179-83. http://dx.doi. org/10.1016/i.ccr.2005.08.008

16. Hahn-Windgassen A, Nogueira V, Chen CC, et al. Akt activates the mammalian target of rapamycin by regulating cellular ATP level and AMPK activity. J Biol Chem 2005;280:32081-9. http://dx.doi. org/10.1074/ibc.M502876200

17. Kalender A, Selvaraj A, Kim SY, et al. Metformin, independent of AMPK, inhibits mTORCl in a rag GTPasedependent manner. Cell Metab 2010;11:390-401. http://dx.doi.org/10.1016/i.cmet.2010.03.014

18. Cho $D$, Signoretti S, Regan $M$, et al. The role of mammalian target of rapamycin inhibitors in the treatment of advanced renal cancer. Clin Cancer Res 2007;13:758s-763s. http://dx.doi.org/10.1158/10780432.CCR-06-1986

19. Hudes $G$, Carducci $M$, Tomczak $P$, et al. Temsirolimus, interferon alfa, or both for advanced renal-cell carcinoma. N Engl J Med 2007;356:2271-81. http://dx.doi.org/10.1056/NEJMoo066838

20. Monami M, Colombi C, Balzi D, et al. Metformin and cancer occurrence in insulin-treated type 2 diabetic patients. Diabetes Care 2011;34:129-31. http://dx.doi.org/10.2337/dc10-1287

21. Bayraktar $S$, Hernadez-Aya LF, Lei $X$, et al. Effect of mefformin on survival outcomes in diabetic patients with triple receptor-negative breast cancer. Cancer 2012;118:1202-11. http://dx.doi.org/10.1002/ cncr. 26439

22. Sun SY, Rosenberg $L M$, Wang $X$, et al. Activation of Akt and elF4E survival pathways by rapamycinmediated mammalian target of rapamycin inhibition. Cancer Res 2005;65:7052-8. http://dx.doi. org/10.1158/0008-5472.CAN-05-0917

23. Zhang Y, Zheng XF. mTOR-independent 4E-BP1 phosphorylation is associated with cancer resistance to mTOR kinase inhibitors. Cell Cycle 2012;11:594-603. http://dx.doi.org/10.4161/cc.11.3.19096

Correspondence: Dr. Hakimi, Memorial Sloan-Kettering Cancer Center, 1275 York Ave New York, NY 10065; hakimia@mskcc.org 